\title{
Oral Candida in Patients with Fixed Orthodontic Appliance: In Vitro Combination Therapy
}

\author{
Wisam Alhamadi, ${ }^{1}$ Rafal J. Al-Saigh, ${ }^{2}$ Nebras N. Al-Dabagh, ${ }^{3}$ and Hussam W. Al-Humadi ${ }^{4}$ \\ ${ }^{1}$ Department of Orthodontics, Dentistry College, University of Babylon, Babylon, Iraq \\ ${ }^{2}$ Department of Clinical \& Laboratory Sciences, Pharmacy College, University of Babylon, Babylon, Iraq \\ ${ }^{3}$ Department of Basic Sciences, Dentistry College, University of Babylon, Babylon, Iraq \\ ${ }^{4}$ Department of Pharmacology \& Toxicology, Pharmacy College, University of Babylon, Babylon, Iraq
}

Correspondence should be addressed to Hussam W. Al-Humadi; alhumadi2010@gmail.com

Received 6 February 2017; Accepted 15 May 2017; Published 8 June 2017

Academic Editor: Andrea Scribante

Copyright (C) 2017 Wisam Alhamadi et al. This is an open access article distributed under the Creative Commons Attribution License, which permits unrestricted use, distribution, and reproduction in any medium, provided the original work is properly cited.

\begin{abstract}
Background. Fixed orthodontic appliance (FOA) increases the cariogenic microorganisms of mouth including candida. The aim was to evaluate the pharmacodynamic effects of some antibacterial drugs in combination with most applicable antifungal agents on candida isolated from patients with FOA. Methods. Three antifungal agents (amphotericin B (AMB), ketoconazole (KET), and itraconazole (ITZ)) and three antibacterial drugs (ciprofloxacin (CIP), doxycycline (DOX), and metronidazole (MET)) with serial concentrations have been used and microdilution broth method has been done for single and combination therapy, then fungal growth was assessed spectrophotometrically, and the combinations were evaluated by bliss independent analysis. Results. According to bliss independent interaction, the synergistic interactions depended on $\Delta E$ values that showed the best for CIP was with AMB $(\Delta E=55.14)$ followed with KET $(\Delta E=41.23)$ and lastly ITR $(\Delta E=39.67)$ at $\mathrm{CIP}=150 \mathrm{mg} / \mathrm{L}$. DOX was optimal with $\mathrm{KET}(\Delta E=$ 42.11) followed with $\operatorname{AMB}(\Delta E=40.77)$ and the lowest with $\operatorname{ITR}(\Delta E=9.12)$ at $\mathrm{DOX}=75 \mathrm{mg} / \mathrm{L}$. MET is the best with $\mathrm{AMB}(\Delta E=$ $40.95)$ and then with ITR $(\Delta E=35.45)$ and finally KET $(\Delta E=15.15)$ at MET $200 \mathrm{mg} / \mathrm{L}$. Moreover, usage of higher concentrations of antibacterial agents revealed inhibitory effects. Conclusion. This study uncovers the optimum antibiotic combination therapy against cariogenic candida with FOA by usage of low therapeutic concentrations.
\end{abstract}

\section{Introduction}

The orthodontic treatment of malocclusions includes the conversion of mechanical energy generated by fixed orthodontic appliance (FOA) forces to biological reaction in teeth and supporting tissues as gingival inflammation and retraction in response to tooth movement [1] which are considered as a low risk and noninvasive orthodontic procedures $[2,3]$. The microbial flora of the mouth is usually a mixture of microorganisms and may consist of more than 200 species [4]. The acid-producing bacteria usually colonize on the tooth surface and surrounding FOA or on orthodontic brackets leading to enamel demineralization $[4,5]$. Nonetheless, the orthodontic brackets have also effect on good oral hygiene leading to plaque accumulation and increase in cariogenic microorganisms in saliva like candida and dental plaque of patients $[5,6]$ as the presence of oral braces increases the frequency of colonization by Candida species [6-8].

Candida species are frequently found in the oral cavity, with a percentage of up to $60 \%$ in young adults $[8,9]$. Candida albicans is the prevalent species; however, other species such as C. dubliniensis, C. parapsilosis C. tropicalis, C. krusei, and C. glabrata have increased in frequency with limited antifungal drugs sensitive to them including polyenes, azoles, allylamines, and echinocandins classes due to the evolution of drug resistance rapidly to Candida species [10].

Nucleic acid or protein synthesis inhibitor antibiotics like fluoroquinolones and aminoglycosides may have a role in the acceleration of the pharmacological action of antifungal drugs $[11,12]$. 
Moreover, the combination of antibiotics with antifungal drugs, simultaneously or sequentially, is often clinically used, but without a good orientation of the consequences; additionally, the role of combined therapy and the effect of antibiotics upon fungal growth should be assessed and evaluated to prevent unwanted drugs interaction and enforced the synergistic effect of these combined therapies [6, 12-14].

Thus, several studies have investigated the effect of FOA on microbial flora of mouth and especially candidal growth but few of them have investigated the pharmacodynamic effect of antibacterial-antifungal combination on candidal growth.

Based on the above, the objective of this study was to evaluate in vitro pharmacodynamic interactions of antibacterial and antifungals combination by microdilution broth checkerboard techniques by using a modification of the CLSI M27-A3 technique [15] and data can be analyzed by bliss question to determine synergistic and antagonistic interactions.

\section{Materials and Methods}

2.1. Patients. 74 patients between 11 and 30 years old (males $36 \%$ and females $64 \%)$ with mean age (19.5 \pm 2$)$ years, required treatment with FOA at the Clinics of Orthodontic, Dentistry College, Babylon University. The study was approved by the ethical committee of College of Dentistry, University of Babylon, Hilla, Babylon, Iraq, in accordance with the Declaration of Helsinki.

2.2. Inclusion Criteria. Eligible patients should not document chronic systemic diseases, should not be receiving immunosuppressive drugs or antimicrobials in the last month, and should not be using antiseptic rinse prior to sampling, with taking consent from patients for sampling.

2.3. Sampling. The study was designed with taking the samples one month after FOA placement. Samples were taken with a sterile swab, which was rubbed rotationally on the oral mucosa and the back of the tongue for each of the patients, in addition to culturing the sterile plastic pads.

2.4. Isolation and Identification of Bacteria. The samples were cultured aerobically on blood agar (blood agar base), MacConkey agar, and chocolate agar (DCM, Netherlands). API system for Staph, API 20 Strept for G+ve cocci, and API 20E for G-ve bacilli (bioMérieux's, France) were used.

2.5. Isolation and Identification of Candida. The samples were cultured aerobically on Sabouraud Dextrose Agar (Difco Laboratories, Basel, Switzerland) and presumptively identified for each species specific of genus Candida in CHROMagar Candida (Hichrome Candida Differential Agar, HiMedia Laboratories, M1297A, India).

2.6. MIC (Minimal Inhibitory Concentrations) Testing for Antifungal Drugs. MIC testing was performed according to the NCCLS approved standard M27-A3 [15] for the reference method of broth dilution antifungal susceptibility testing of yeasts. An inoculum suspension was prepared from new cultures with a counting chamber in order to obtain $2 \times 10^{4}$ conidia/mL in $10.4 \mathrm{~g} / \mathrm{L}$ RPMI 1640 with glutamine without sodium bicarbonate (Sigma-Aldrich, St. Louis, MO) and $0.165 \mathrm{M}$ morpholinepropanesulfonic acid buffer (Invitrogen, Carlsbad, CA), pH 7.0, with $100 \mathrm{mg} / \mathrm{L}$ chloramphenicol (Sigma-Aldrich, St. Louis, MO). The reference strain was Candida albicans (ATCC 10231) [15].

The MIC of amphotericin B (AMB) (Bristol-Myers Squibb, Princeton, NJ), ketoconazole (KET) (Pfizer Inc., New York, NY, USA), and itraconazole (ITZ) (Pfizer, New York, NY, USA) as antifungal drugs was tested by CLSI method after $24 \mathrm{~h}$ of incubation, and fungal growth was assessed spectrophotometrically. For spectrophotometric assessment, fungal growth was measured at $405 \mathrm{~nm}$. The relative optical density (OD) was 405 for each well and drug concentration, in relation to the control well.

All stock antimicrobial solutions were stored in onetime-use aliquots at $-70^{\circ} \mathrm{C}$. The tests were carried out in duplicate in sterile plastic microplates (TPP Zellkultur Test Plate 96F, Switzerland) with MICs of reference strain being $0.25-1.0 \mathrm{mg} / \mathrm{L}$ for $\mathrm{AMB}, 1.0-2.0 \mathrm{mg} / \mathrm{L}$ for $\mathrm{KET}$, and $0.5-1.0 \mathrm{mg} / \mathrm{L}$ for ITZ.

2.7. The Drugs Combination. The combination screens were performed in 96-well plates. Each well of the microplate received an increasing concentration with maximum concentration $\left(C_{\max }\right)$ ranging from 0.015 to $32 \mathrm{mg} / \mathrm{L}$ for antifungal agents. Every well had $100-\mu \mathrm{L}$ of RPMI with inocula and $100-\mu \mathrm{L}$ of antifungal agents without antibiotics or $50 \mu \mathrm{L}$ of antifungal agents and $50 \mu \mathrm{L}$ of antibiotics in other columns of the microplates with 7 concentrations $\left(C_{\max }\right)$ from antibiotics ciprofloxacin (CIP), doxycycline (DOX), and metronidazole (MET) (Sigma-Aldrich, St. Louis, MO). The serial dilutions were performed to achieve maximal dilutions.

All the assays were carried out in duplicate. The treated microplates were incubated at $35^{\circ} \mathrm{C}$ for $24 \mathrm{~h}$. The results were evaluated by optical density of spectrophotometer as relative values at $405 \mathrm{~nm}[16]$.

2.8. Bliss Independence Interaction Analysis. Bliss independence is described by the equation $I_{\mathrm{IND}}=I_{A}+I_{B}-I_{A} \times I_{B}$ for a certain combination of $(x)$ concentration of $\operatorname{drug} A$ and (y) concentration of $\operatorname{drug} B$ where $I_{A}$ is antifungal at $(x)$ concentration alone, $I_{B}$ are antibiotics at $(y)$ concentration alone, and $I_{\text {IND }}$ is expected fungal growth with antibiotic as $100 \%$ and antifungal combination as $(x)$ concentration of antifungal with $(y)$ concentration of antibiotics. Therefore, fungal growth with antibiotic or antifungal $(I)$ is equal to $1-E$.

Bliss equation can be transformed to $E_{\mathrm{IND}}=E_{A} \times E_{B}$, where $E_{A}$ and $E_{B}$ are difference in fungal growth with antifungal and antibiotic, respectively. This difference is expected values $\left(E_{\mathrm{IND}}\right)$ and the experimentally observed values $\left(E_{\mathrm{OBS}}\right)$; thus $\Delta I=E_{\mathrm{IND}}-E_{\mathrm{OBS}}$. If $\Delta E$ is $>0\left(E_{\mathrm{OBS}}<E_{\mathrm{IND}}\right)$, Bliss synergy is concluded for that particular combination. If $\Delta E$ is $<0\left(E_{\mathrm{OBS}}>E_{\mathrm{IND}}\right)$, hence, Bliss antagonism is concluded 
TABLE 1: Pharmacodynamic data of candida isolated from patients with fixed orthodontic appliance. MIC: minimal inhibitory concentration (mg/L); AMB: amphotericin B; KET: ketoconazole; ITR: itraconazole.

\begin{tabular}{|c|c|c|c|c|}
\hline Candidal isolates & $\begin{array}{c}\text { Associated } \\
\text { bacteria }\end{array}$ & MIC for AMB & MIC for KET & MIC for ITR \\
\hline C. albicans (1) & S. viridans & 0.5 & 1.0 & 1.0 \\
\hline C. albicans (2) & S. viridans & 0.5 & 1.0 & 1.0 \\
\hline C. albicans (3) & S. viridans & 0.5 & 1.0 & 1.0 \\
\hline C. albicans (4) & S. viridans & 0.5 & 1.0 & 1.0 \\
\hline C. albicans (5) & $\begin{array}{l}\text { P. aeruginosa, } \\
\text { S. viridans }\end{array}$ & 0.5 & 2.0 & 2.0 \\
\hline C. albicans (6) & P. aeruginosa & 0.5 & 2.0 & 1.0 \\
\hline C. albicans (7) & P. aeruginosa & 0.5 & 2.0 & 1.0 \\
\hline C. albicans (8) & $\begin{array}{c}\text { E. coli, } \\
\text { S. viridans }\end{array}$ & 0.5 & 2.0 & 2.0 \\
\hline C. albicans (9) & E. coli & 0.5 & 1.0 & 1.0 \\
\hline C. albicans (10) & E. coli & 0.5 & 1.0 & 2.0 \\
\hline C. dubliniensis (1) & S. viridans & 0.5 & 1.0 & 1.0 \\
\hline C. dubliniensis (2) & S. viridans & 0.5 & 2.0 & 1.0 \\
\hline C. dubliniensis (3) & E. coli & 0.5 & 2.0 & 2.0 \\
\hline C. parapsilosis (1) & S. viridans & 0.5 & 1.0 & 1.0 \\
\hline C. parapsilosis (2) & $\begin{array}{l}\text { S. aureus, } \\
\text { S. viridans }\end{array}$ & 1.0 & 1.0 & 1.0 \\
\hline C. krusei & P. aeruginosa & 0.5 & 4.0 & 2.0 \\
\hline C. glabrata & S. viridans & 0.25 & 1.0 & 1.0 \\
\hline C. tropicalis & S. viridans & 0.25 & 1.0 & 1.0 \\
\hline
\end{tabular}

for that particular combination. For each combination between antifungal and antibiotic drugs, its statistical significance was assessed by Student's $t$-test $[17,18]$.

The statistical significance was $p$ value less than 0.05 and all statistical analysis was performed with the software Prism 5.01 (GraphPad Inc., La Jolla, CA).

\section{Results and Discussion}

In our study, the prevalence of cariogenic candida in FOA patients was about $24 \%$ from collected samples, which was in accordance with previous studies that showed about $30 \%$ $[2,19,20]$; furthermore, with all candida isolates being associated with bacterial growth (one or more bacterial isolates) (Table 1) [6], this superadded infection may exert an effect on the virulence of candida. Some studies showed that once the microorganisms (bacteria and fungi) are established in the plaque, they do not inhibit each other, but rather they seem to exert a synergistic effect for caries formation $[6,19]$. Our findings supported the previous results that revealed $S$. viridans bacteria as an abundant oral streptococcal infection associated with candida in patients with FOA $[6,21,22]$.

3.1. In Vitro MICs. In vitro studies for MICs of AMB, KET, and ITR against each candida isolate in addition to associated bacterial pathogens for each isolate were shown in Table 1 while MICs for three antibiotics were inactive for candida isolates. The mean of MICs (mMICs) for AMB was $0.5 \mathrm{mg} / \mathrm{L}$, for KET was $2.0 \mathrm{mg} / \mathrm{L}$, and for ITR was $1.0 \mathrm{mg} / \mathrm{L}$ (Table 1).
The results in checkerboard data with intermediate growth could be undetected visually in single-drug experiments by using twofold dilutions. For example, an MIC of $2 \mathrm{mg} / \mathrm{L}$ in a twofold dilution scheme may correspond to any concentration between 1 and $2 \mathrm{mg} / \mathrm{L}$ [23-26]; moreover, in vivo study showed that the two microorganisms represent a triggering or supporting factor for the periodontitis development in FOA patients [27].

3.2. Pharmacodynamic Effects of Combinations. The mMICs for $\mathrm{AMB}$ was decreased from 0.5 to $0.25 \mathrm{mg} / \mathrm{L}$ in the presence of CIP with $C_{\max }$ from 100 to $200 \mathrm{mg} / \mathrm{L}$ (Figure 1) and of MET with $C_{\max }$ from 150 to $200 \mathrm{mg} / \mathrm{L}$ (Figure 3) while there was no change of mMICs with DOX (Figure 2); moreover, mMICs was increased to 1.0 and $2.0 \mathrm{mg} / \mathrm{L}$ with CIP at $C_{\max }$ between 300 and $350 \mathrm{mg} / \mathrm{L}$ (Figure 1), with DOX at $200 \mathrm{mg} / \mathrm{L} C_{\max }$ (Figure 2), and with MET at $C_{\max }$ between 300 and $350 \mathrm{mg} / \mathrm{L}$ (Figure 3).

The mMICs of KET also decreased from 2.0 to $1.0 \mathrm{mg} / \mathrm{L}$ in the presence of CIP with $C_{\max }$ of 150 to $200 \mathrm{mg} / \mathrm{L}$ (Figure 1), of DOX with $C_{\max }$ from 75 to 100 (Figure 2), and of MET at $150 \mathrm{mg} / \mathrm{L} C_{\max }$ (Figure 3) only; furthermore, mMICs was increased to 4.0 and $8.0 \mathrm{mg} / \mathrm{L}$ with CIP at $C_{\max }$ between 300 and $350 \mathrm{mg} / \mathrm{L}$ (Figure 1), with DOX at $C_{\max }$ between 150 and $200 \mathrm{mg} / \mathrm{L}$ (Figure 2), and with MET at $C_{\max }$ between 250 and $350 \mathrm{mg} / \mathrm{L}$ (Figure 3).

Regarding the mMICs of ITR, it was decreased from 1.0 to $0.5 \mathrm{mg} / \mathrm{L}$ in the presence of CIP with $C_{\max }$ from 150 to 


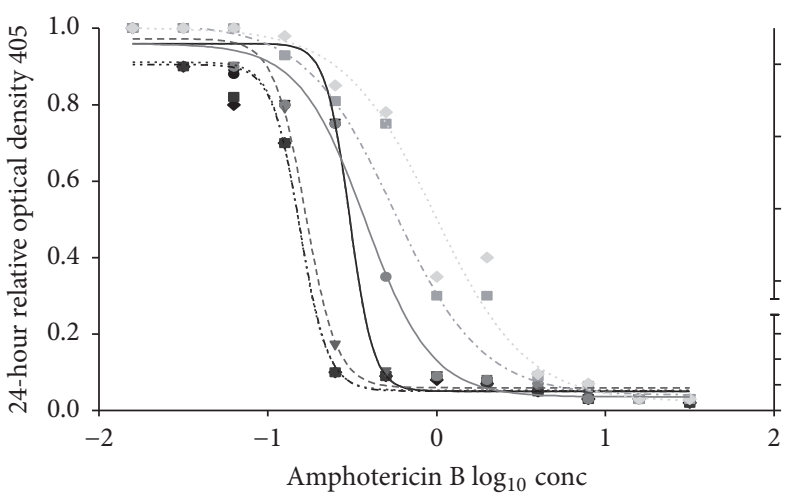

- Without antibiotics _ - - Ciprofloxacin $200 \mathrm{mg} / \mathrm{L}$

- - Ciprofloxacin $50 \mathrm{mg} / \mathrm{L} \quad \longrightarrow$ Ciprofloxacin $250 \mathrm{mg} / \mathrm{L}$

•- Ciprofloxacin $100 \mathrm{mg} / \mathrm{L} \quad$ - - Ciprofloxacin $300 \mathrm{mg} / \mathrm{L}$

- . Ciprofloxacin $150 \mathrm{mg} / \mathrm{L} \ldots$ Ciprofloxacin $350 \mathrm{mgL}$

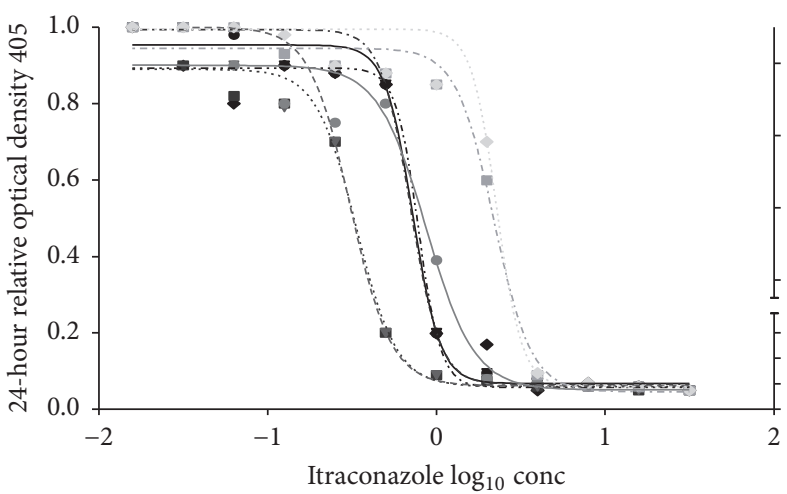

$\rightarrow$ Without antibiotics $\quad-v-$ Ciprofloxacin $200 \mathrm{mg} / \mathrm{L}$

- - Ciprofloxacin $50 \mathrm{mg} / \mathrm{L} \longrightarrow$ Ciprofloxacin $250 \mathrm{mg} / \mathrm{L}$

..๑. Ciprofloxacin $100 \mathrm{mg} / \mathrm{L}$ - - Ciprofloxacin $300 \mathrm{mg} / \mathrm{L}$

-. Ciprofloxacin $150 \mathrm{mg} / \mathrm{L} \ldots$ Ciprofloxacin $350 \mathrm{mgL}$

(a)

(b)

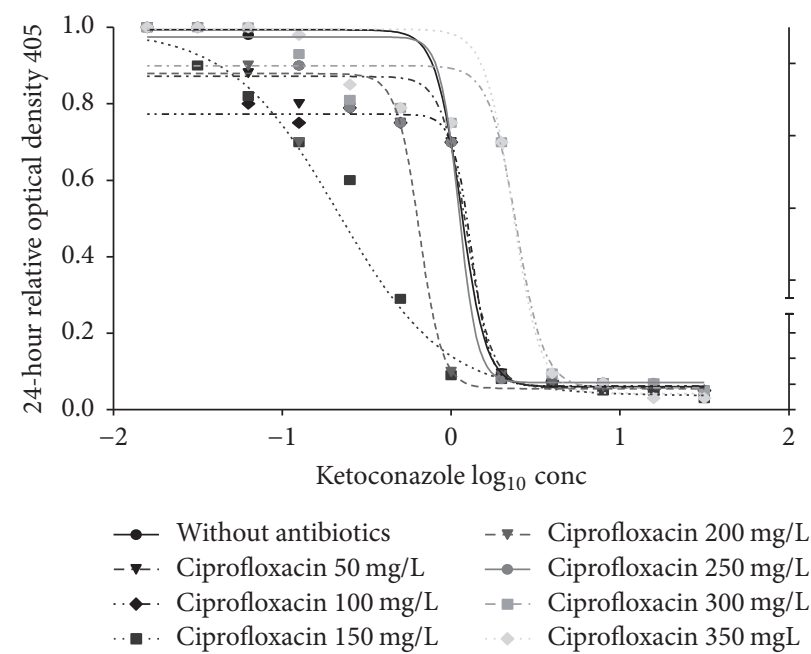

(c)

FIgURE 1: In vitro pharmacodynamic effects of ciprofloxacin (mg/L) combined with amphotericin B (mg/L); ketoconazole (mg/L); itraconazole $(\mathrm{mg} / \mathrm{L})$ as $\log _{10}$ concentration on candida isolated from patients with fixed orthodontic appliance.

$200 \mathrm{mg} / \mathrm{L}$ (Figure 1) and of DOX with $C_{\max }$ from 75 to 100 (Figure 2) while there was no change of mMICs with MET (Figure 3); in addition to that, mMICs was increased to 2.0 and $4.0 \mathrm{mg} / \mathrm{L}$ with CIP at $C_{\max }$ between 300 and $350 \mathrm{mg} / \mathrm{L}$ (Figure 1), with DOX at $C_{\max }$ between 125 and $200 \mathrm{mg} / \mathrm{L}$ (Figure 2), and with MET at $C_{\max }$ between 250 and $350 \mathrm{mg} / \mathrm{L}$ (Figure 3).

Drugs' combinations were presented as two-drug combinations of antifungal and antibacterial drugs with different modes of action. Some studies showed that the growth impairment of candida appeared to be the sum of individual contributions of either chemical to the cells' fitness, rather than a synergistic effect [13,28,29].

Regarding DOX, antimicrobial agent that prevents bacterial protein synthesis potentiates the antifungal activity of azole group against candida infection (dosage-dependent); moreover, it converts the action of this antifungal group from fungistatic to fungicidal and prevents the onset of drug resistance later. Additionally, DOX appears to have a major impact on prevention of azole tolerance [13].

\subsection{Analysis of Pharmacodynamics Effect between Antibiotics} and Antifungals according to Bliss Independence Analysis. According to bliss independence interaction analysis on clinical candidal isolates, the effects of antibacterial-antifungal combination were demonstrated by $\Delta E$ values where the MIC with antibacterial is lesser than without it $\left(E_{\mathrm{OBS}}<E_{\mathrm{IND}}\right)$.

According to these data, the best combination of AMB was with CIP where $\Delta E$ was 55.14 while with MET, $\Delta E=$ 40.95 , and with DOX, $\Delta E=40.77(p<0.001)$ at $C_{\max }$ for $\mathrm{AMB}=0.25 \mathrm{mg} / \mathrm{L}$.

Regarding KET, the best synergism was with both DOX and CIP where $\Delta E$ were 42.11 and $41.23(p<0.001)$ at $C_{\max }$ for $\mathrm{DOX}=100 \mathrm{mg} / \mathrm{L}$ and $\mathrm{CIP}=150 \mathrm{mg} / \mathrm{L}$, respectively, while 


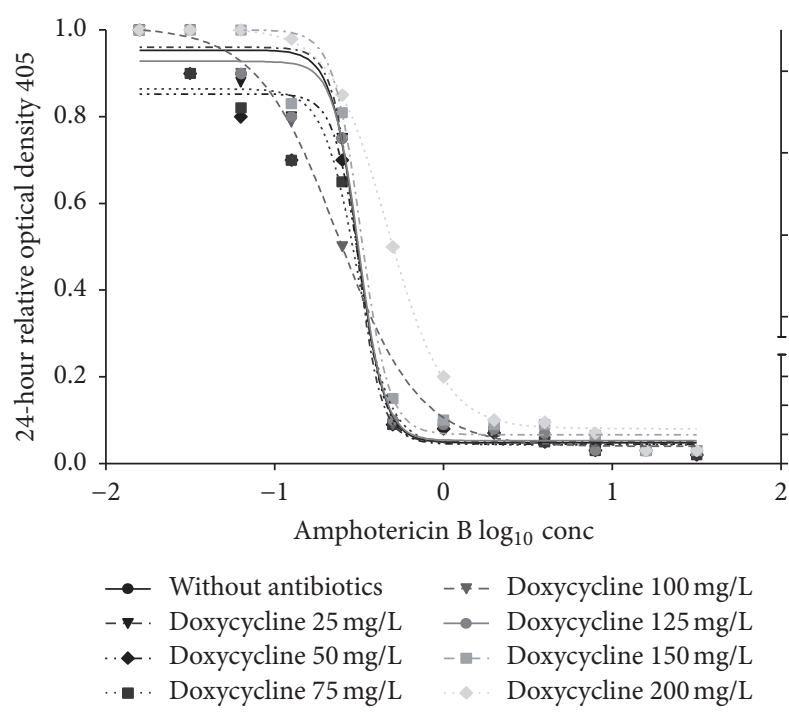

(a)

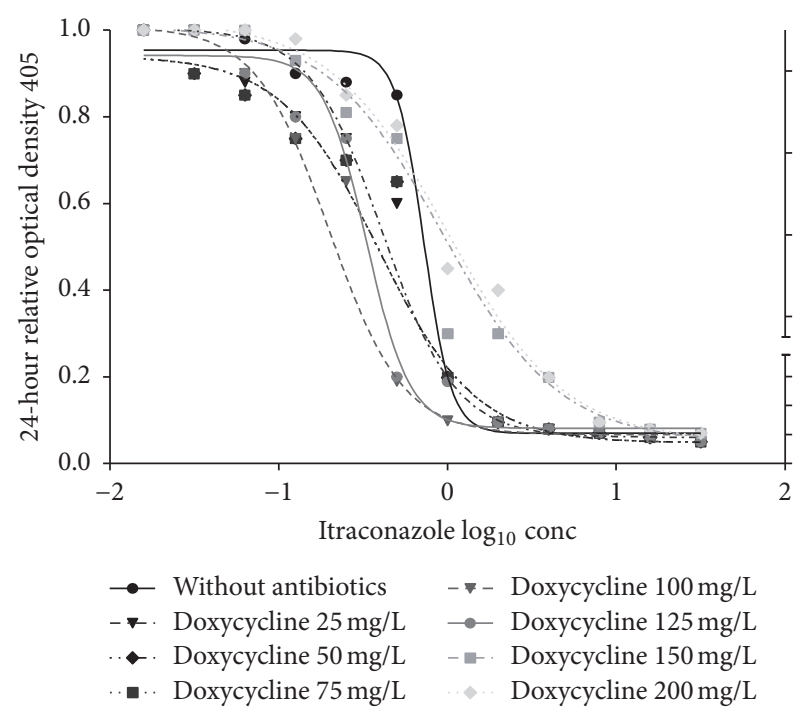

(b)

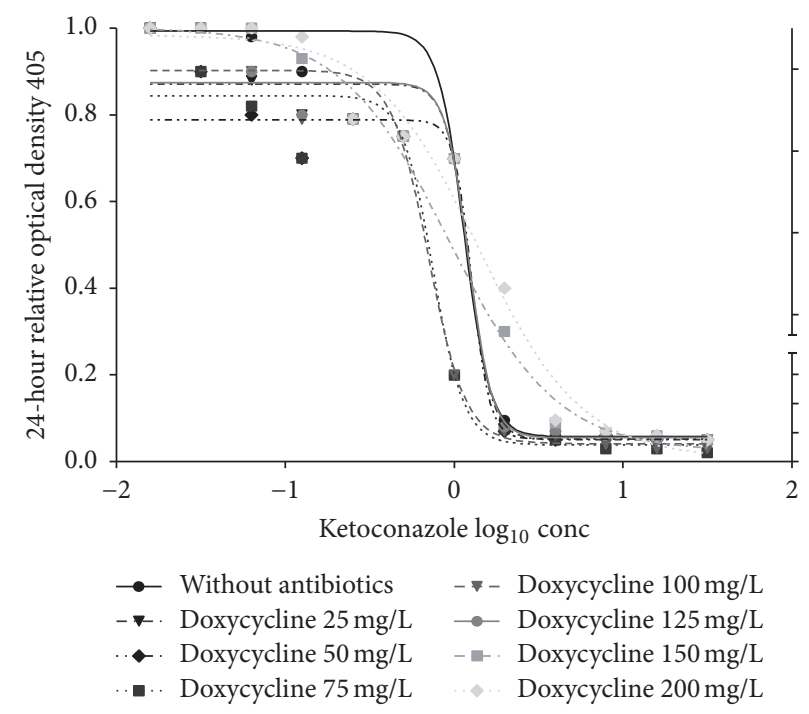

(c)

FIGURE 2: In vitro pharmacodynamic effects of doxycycline (mg/L) combined with amphotericin B (mg/L); ketoconazole (mg/L); itraconazole $(\mathrm{mg} / \mathrm{L})$ as $\log _{10}$ concentration on candida isolated from patients with fixed orthodontic appliance.

with MET, $\Delta E=15.15(p<0.05)$ at $C_{\max }=150 \mathrm{mg} / \mathrm{L}, C_{\max }$ for $\mathrm{KET}=1.0 \mathrm{mg} / \mathrm{L}$.

Furthermore, ITR data showed that the best synergism was with CIP where $\Delta E$ was $39.67(p<0.001)$ and with MET where $\Delta E$ was $35.45(p<0.01)$ while with $\mathrm{DOX}, \Delta E=9.12$ $(p<0.05)$ at $C_{\max }$ for ITR $=0.5 \mathrm{mg} / \mathrm{L}$ (Figure 4$)$.

On the other hand, $\Delta E$ for other concentrations were lower than 1.0; that means there was no synergism while $\Delta E$ values decreased to $<-19.50$ for $\mathrm{CIP}_{C_{\max }}>300 \mathrm{mg} / \mathrm{L}$, $<-13.85$ for DOX $C_{\max }>150 \mathrm{mg} / \mathrm{L}$, and $<-21.33$ for MET $C_{\max }>300 \mathrm{mg} / \mathrm{L}(p<0.001)$.

The results were evaluated by bliss interaction analysis in order to determine the synergy and antagonism.

There are many in vitro studies exploring the interactions between antifungal compounds and some antibacterial agents depending on use of different agents with certain concentrations. In our study, serial concentrations for different agents have been chosen to evaluate the interaction more deeply and specifically. Aminoglycosides exhibit no antifungal activity on their own, but with amphotericin B they appear to facilitate the drug's entry into the fungal cell, allowing it to inhibit DNA transcription. Indeed, synergy has been found for amphotericin B plus aminoglycosides against isolates of Candida spp., Aspergillus spp., and Fusarium species [30, 31]. Aminoglycosides also enhance the effects in vitro of azole agents [31, 32]. Several studies have also shown synergy between antifungal agents and the fluoroquinolones such as ciprofloxacin, levofloxacin, and ofloxacin and the macrolides against some fungal species [33-36]. 


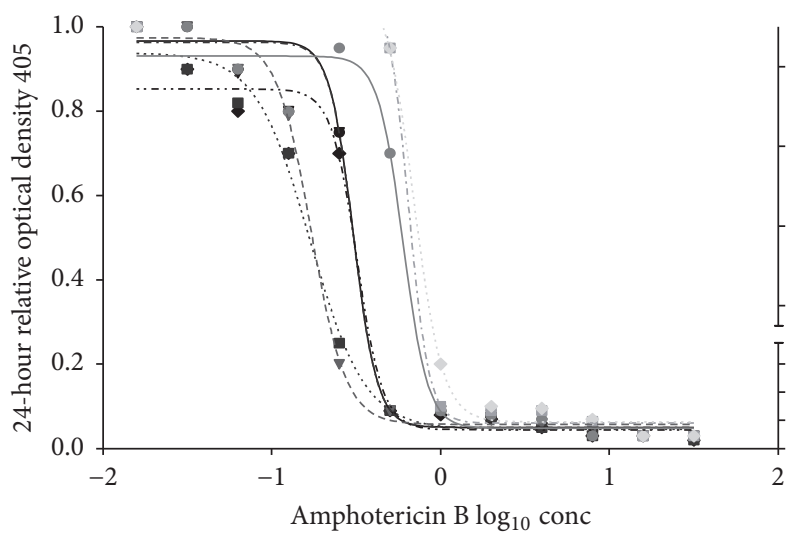

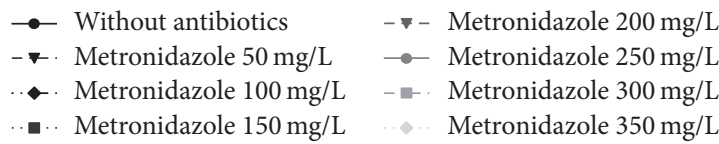

(a)

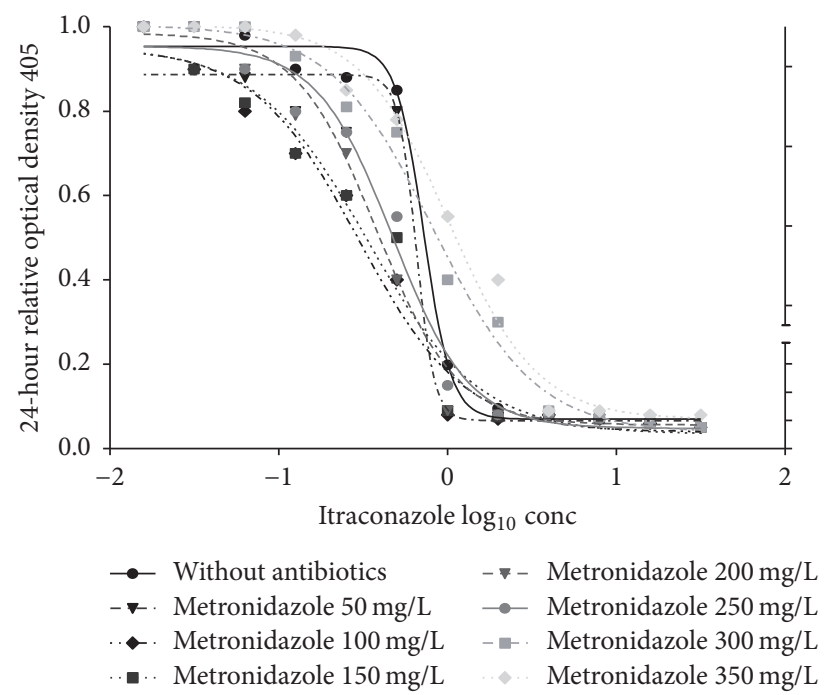

(b)

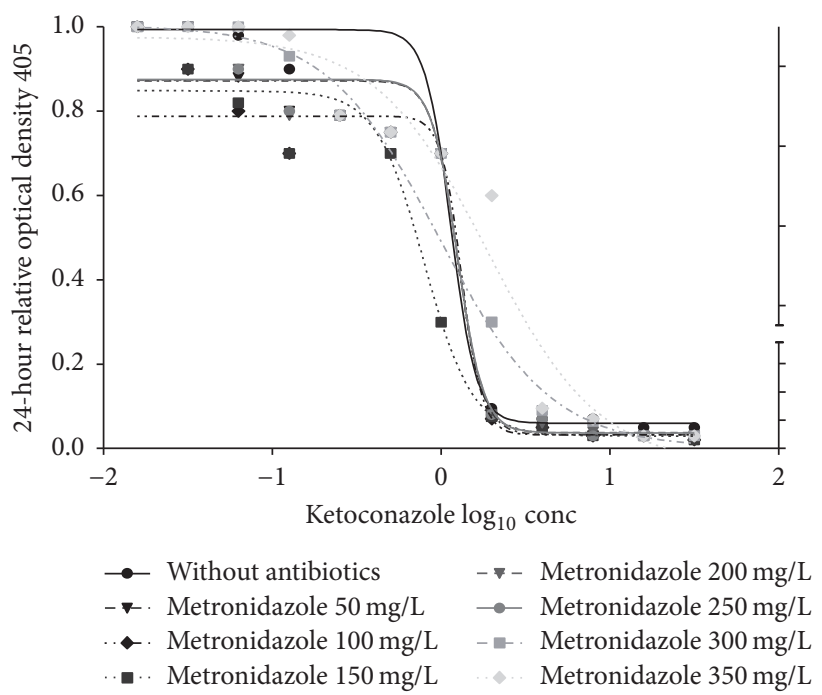

(c)

Figure 3: In vitro pharmacodynamic effects of metronidazole $(\mathrm{mg} / \mathrm{L})$ combined with amphotericin B (mg/L); ketoconazole (mg/L); itraconazole $(\mathrm{mg} / \mathrm{L})$ as $\log _{10}$ concentration on candida isolated from patients with fixed orthodontic appliance.

In contrast to in vivo experimental models that may allow clinical effectiveness to be predicted and mimicking to humans infection $[37,38]$, the in vitro susceptibility testing determines the inherent susceptibilities of organisms to antimicrobial agents which are considered more reliable for ascertaining whether an antimicrobial agent is suitable for treating a human infection and assessing combinations of antifungal-antibacterial agents. Many studies revealed low statistical power to detect significant differences in efficacy of different therapies and raise doubts about the validity of their results for application of antifungal agents that are recommended for clinical use. The inhibition of fungal DNA or protein synthesis might represent a new target for future antifungal agents. The role of DNA or protein synthesis inhibitor antibiotics in combination with antifungal agents as a new therapeutic strategy against candida had been assessed in many studies but not improved yet. On the other hand, the synergy of pharmacokinetic data for these combinations had increased the fungicidal effect of antifungal compounds [31, 36, 39-41].

In conclusion, this study uncovers the optimum antifungal-antibacterial combination therapy against cariogenic candida in dose specific manner by usage of low therapeutic concentrations in patients with FOA. The best synergism was between $\mathrm{AMB}$ and CIP and the lowest synergism was between ITR and DOX at low therapeutic concentrations while the antagonistic interactions were detected at highest therapeutic concentrations of antibacterial agents. 


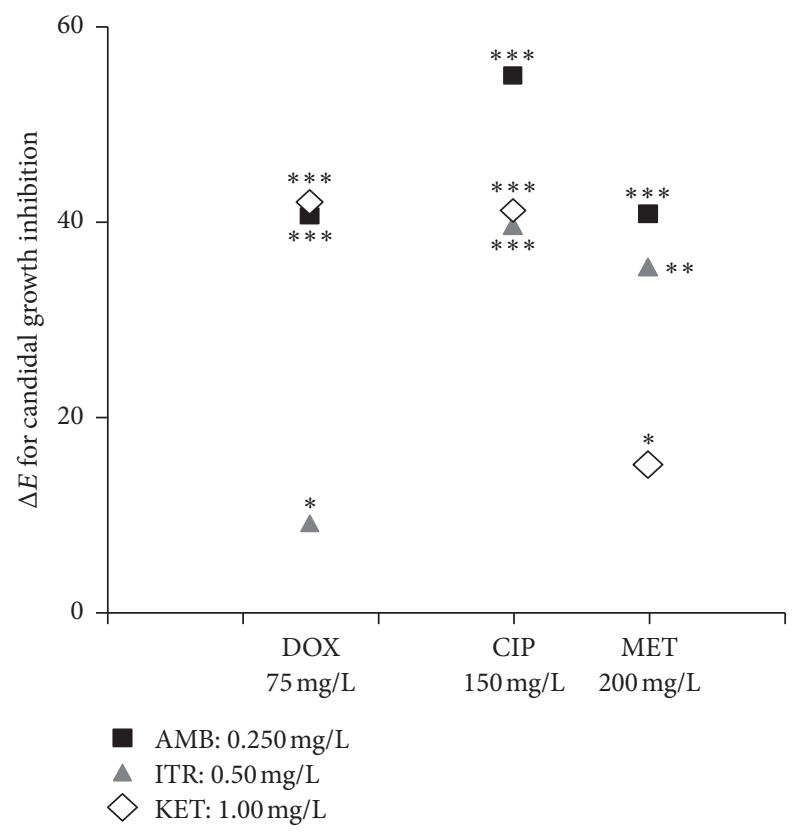

FIGURE 4: The synergistic effects of antibiotics-antifungal combination according to bliss independence interaction analysis on clinical candida isolated from patients with fixed orthodontic appliance. AMB: amphotericin B (mg/L); KET: ketoconazole (mg/L); ITR: itraconazole (mg/L), CIP: ciprofloxacin, DOX: doxycycline, MET: metronidazole. The number of asterisks $(*)$ corresponds to the level of the statistical significance $\left({ }^{*} P<0.05,{ }^{* *} P<0.01\right.$, and ${ }^{* * *} P<$ $0.001)$.

\section{Conflicts of Interest}

The authors declare that there are no conflicts of interest.

\section{Acknowledgments}

The authors thank the Coordination for the Improvement of Babylon University/College of Pharmacy and College of Dentistry for supporting this study by providing the laboratory tools and equipment.

\section{References}

[1] H. F. Saloom, H. S. Mohammed-Salih, and S. F. Rasheed, "The influence of different types of fixed orthodontic appliance on the growth and adherence of microorganisms (in vitro study)," Journal of Clinical and Experimental Dentistry, vol. 5, no. 1, pp. e36-e41, 2013.

[2] M. I. Brusca, O. Chara, L. Sterin-Borda, and A. C. Rosa, "Influence of different orthodontic brackets on adherence of microorganisms in vitro," Angle Orthodontist, vol. 77, no. 2, pp. 331-336, 2007.

[3] T. Arendorf and M. Addy, "Candidal carriage and plaque distribution before, during and after removable orthodontic appliance therapy," Journal of Clinical Periodontology, vol. 12, no. 5, pp. 360-368, 1985.

[4] M. Wilson, "Bacterial biofilms and human disease," Science Progress, vol. 84, no. 3, pp. 235-254, 2001.
[5] K. Hibino, R. W. Wong, U. Hagg, and L. P. Samaranayake, "The effects of orthodontic appliances on the human mouth," International Journal of Paediatric Dentistry, vol. 19, p. 308, 2009.

[6] S. N. Rammohan, C. S. Juvvadi Gandikota, P. Challa, R. Manne, and A. Mathur, "Adherence of Streptococcus mutans and Candida albicansto different bracket materials," Journal of Pharmacy and Bioallied Science, vol. 4, pp. S212-S216, 2012.

[7] F. Wheel-Gordillo and S. E. Hernández-Solís, "Prevalence of Candida albicansisolated from the oral cavity cancer patients," Latinoam Odontol Rev, pp. 38-41, 2008.

[8] S. E. Wheel-Gordillo F Hernandez-Solis, W. Ordoñez-Sanchez, J. L. Villamil-Urzaiz, and C. Godoy-Montañez, "Carriers Candidaoral in patients treated at a dental clinic in Tabasco, Mexico," Revista Odontológica Latinoamericana, vol. 3, pp. 4548, 2011.

[9] E. Khanpayeh, A. A. Jafari, and Z. Tabatabaei, "Comparison of salivary Candida profile in patients with fixed and removable orthodontic appliances therapy," Iranian Journal of Microbiology, vol. 6, no. 4, pp. 263-268, 2014.

[10] S. E. Hernández-Solís, F. Rueda-Gordillo, and R. A. RojasHerrera, "Proteinase activity in Candida albicans strains isolated from the oral cavity of immunocompromised patients, with oral candidiasis and in healthy subjects," Revista Iberoamericana de Micologia, vol. 31, no. 2, pp. 137-140, 2014.

[11] G. M. Eliopoulos and R. C. Moellering Jr., Antibiotics in laboratory medicine, ed Lorian V. (Williams and Wilkins,Baltimore, Md), 4th edition, 1996.

[12] L. Lown, B. M. Peters, C. J. Walraven, M. C. Noverr, and S. A. Lee, "An optimized lock solution containing micafungin, ethanol and doxycycline inhibits candida albicans and mixed C. albicans-staphyloccoccus aureus biofilms," PLoS ONE, vol. 11, no. 7, Article ID e0159225, 2016.

[13] A. Fiori and P. Van Dijck, "Potent synergistic effect of doxycycline with fluconazole against Candida albicans is mediated by interference with iron homeostasis," Antimicrobial Agents and Chemotherapy, vol. 56, no. 7, pp. 3785-3796, 2012.

[14] M. M. Azevedo, R. Teixeira-Santos, A. P. Silva et al., "The effect of antibacterial and non-antibacterial compounds alone or associated with antifugals upon fungi," Frontiers in Microbiology, vol. 6, 2015.

[15] Clinical and Laboratory Standards Institute, Reference method for broth dilution antifungal susceptibility testing of yeasts: approved standard, CLSI document M27-A3, Wayne, PA, USA, 3rd edition, 2008.

[16] P. S. Ocampo, V. Lázár, B. Papp et al., "Antagonism between bacteriostatic and bactericidal antibiotics is prevalent," Antimicrobial Agents and Chemotherapy, vol. 58, no. 8, pp. 4573-4582, 2014.

[17] WR. Greco, G. Bravo, and J. C. Parsons, "The search for synergy: a critical review from a response surface perspective," Pharmacological Reviews, vol. 47, pp. 331-385, 1995.

[18] H. Al-Humadi, "he Neuroprotective Effect of L-Cysteine Towards Cadmium or Nickel Neurotoxicity on Adult Rat Brain Antioxidant Status and Acetylcholinesterase Activity," Kerbala Jorunal of Medicine, vol. 8, no. 1, pp. 2043-2048, 2015.

[19] U. Hägg, P. Kaveewatcharanont, Y. H. Samaranayake, and L. P. Samaranayake, "The effect of fixed orthodontic appliances on the oral carriage of Candida species and Enterobacteriaceae," European Journal of Orthodontics, vol. 26, no. 6, pp. 623-629, 2004.

[20] S. G. Arslan, N. Akpolat, J. D. Kama, T. Ozer, and O. Hamamci, "One-year follow-up of the effect of fixed orthodontic treatment 
on colonization by oral candida," Journal of Oral Pathology \& Medicine, vol. 37, pp. 26-29, 2008.

[21] P. Cernochova, P. Augustin, and A. Fassmann, "Occcurance of periodontal pathogen in patient treated with fixed orthodontic appliance. Scripta Medica," Scripta Medica, vol. 81, no. 2, pp. 8596, 2008.

[22] D. K. Anthola, A. Francesco, and V. P. Gusbert, "Clinical and microbiological effect of fixed orthodontic appliance," Journal of Clinical Periodontology, vol. 14, no. 6, pp. 326-333, 2009.

[23] W. Shi, Z. Chen, X. Chen, L. Cao, P. Liu, and S. Sun, “The combination of minocycline and fluconazole causes synergistic growth inhibition against Candida albicans: An in vitro interaction of antifungal and antibacterial agents," FEMS Yeast Research, vol. 10, no. 7, pp. 885-893, 2010.

[24] F. R. Pires, E. B. D. Santos, P. R. F. Bonan, O. P. De Almeida, and M. A. Lopes, "Denture stomatitis and salivary Candida in Brazilian edentulous patients," Journal of Oral Rehabilitation, vol. 29, no. 11, pp. 1115-1119, 2002.

[25] S. A. Messer, D. J. Diekema, L. Boyken, S. Tendolkar, R. J. Hollis, and M. A. Pfaller, "Activities of micafungin against 315 invasive clinical isolates of fluconazole-resistant candida spp.," Journal of Clinical Microbiology, vol. 44, no. 2, pp. 324-326, 2006.

[26] H. Al-Humadi, "Impact of human serum on pharmacodynamic action of echinocandins against aspergillus spp.: an in vitro study," MEDICALJB, vol. 12, no. 3, pp. 603-611, 2015.

[27] P. Nelson-Filho, R. M. A. Valdez, M. C. D. Andrucioli et al., "Gram-negative periodontal pathogens and bacterial endotoxin in metallic orthodontic brackets with or without an antimicrobial agent: An in-vivo study," American Journal of Orthodontics and Dentofacial Orthopedics, vol. 140, no. 6, pp. e281-e287, 2011.

[28] F. C. Odds, A. B. Abbott, G. Pye, and P. F. Troke, "Improved method for estimation of azole antifungal inhibitory concentrations against candida species, based on azole/antibiotic interactions," Medical Mycology, vol. 24, no. 4, pp. 305-311, 1986.

[29] B. G. Oliver, P. M. Silver, C. Marie, S. J. Hoot, S. E. Leyde, and T. C. White, "Tetracycline alters drug susceptibility in Candida albicans and other pathogenic fungi," Microbiology, vol. 154, no. 3, pp. 960-970, 2008.

[30] M. A. Pfaller, D. J. Sheehan, and J. H. Rex, "Determination of Fungicidal Activities against Yeasts and Molds: Lessons Learned from Bactericidal Testing and the Need for Standardization," Clinical Microbiology Reviews, vol. 17, no. 2, pp. 268-280, 2004.

[31] C. J. Clancy, Y. C. Yu, A. Lewin, and M. H. Nguyen, "Inhibition of RNA synthesis as a therapeutic strategy against Aspergillus and Fusarium: Demonstration of in vitro synergy between rifabutin and amphotericin B," Antimicrobial Agents and Chemotherapy, vol. 42, no. 3, pp. 509-513, 1998.

[32] S. G. Arslan, N. Akpolat, J. D. Kama, T. Ozer, and O. Hamamci, "One-year follow-up of the effect of fixed orthodontic treatment on colonization by oral candida," Journal of Oral Pathology \& Medicine, vol. 37, pp. 26-29, 2008.

[33] W. J. Steinbach, D. A. Stevens, and D. W. Denning, "Combination and Sequential Antifungal Therapy for Invasive Aspergillosis: Review of Published In Vitro and In Vivo Interactions and 6281 Clinical Cases from 1966 to 2001," Clinical Infectious Diseases, vol. 37, no. 3, pp. S188-S224, 2003.

[34] R. G. Vitale, J. Afeltra, G. S. de Hoog, A. J. Rijs, and P. E. Verweij, "In vitro activity of amphotericin B and itraconazole in combination with flucytosine, sulfadiazine and quinolones against Exophiala spinifera," Journal of Antimicrobial Chemotherapy, vol. 51, no. 5, pp. 1297-1300, 2003.
[35] M. A. Petrou and T. R. Rogers, "In-vitro activity of antifungal agents in combination with four quinolones," Drugs under Experimental and Clinical Research, vol. 14, no. 1, pp. 9-18, 1988.

[36] E. Sasaki, S. Maesaki, Y. Miyazaki et al., "Synergistic effect of ofloxacin and fluconazole against azole-resistant Candida albicans," Journal of Infection and Chemotherapy, vol. 6, no. 3, pp. 151-154, 2000.

[37] O. Zak and T. O'Reilly, "Animal models in the evaluation of antimicrobial agents," Antimicrobial Agents and Chemotherapy, vol. 35, no. 8, pp. 1527-1531, 1991.

[38] A. Selmecki, M. Gerami-Nejad, C. Paulson, A. Forche, and J. Berman, "An isochromosome confers drug resistance in vivo by amplification of two genes, ERG11 and TAC1," Molecular Microbiology, vol. 68, no. 3, pp. 624-641, 2008.

[39] B. Auclair, S. E. Berning, G. A. Huitt, and C. A. Peloquin, "Potential interaction between itraconazole and clarithromycin," Pharmacotherapy, vol. 19, no. 12, pp. 1439-1444, 1999.

[40] M. Hirano, Y. Takeuchi, N. Matsumori, M. Murata, and T. Ide, "Channels formed by amphotericin B covalent dimers exhibit rectification," Journal of Membrane Biology, vol. 240, no. 3, pp. 159-164, 2011.

[41] K. Maebashi, M. Kudoh, Y. Nishiyama et al., "A novel mechanism of fluconazole resistance associated with fluconazole sequestration in Candida albicans isolates from a myelofibrosis patient," Microbiology and Immunology, vol. 46, no. 5, pp. 317326, 2002. 

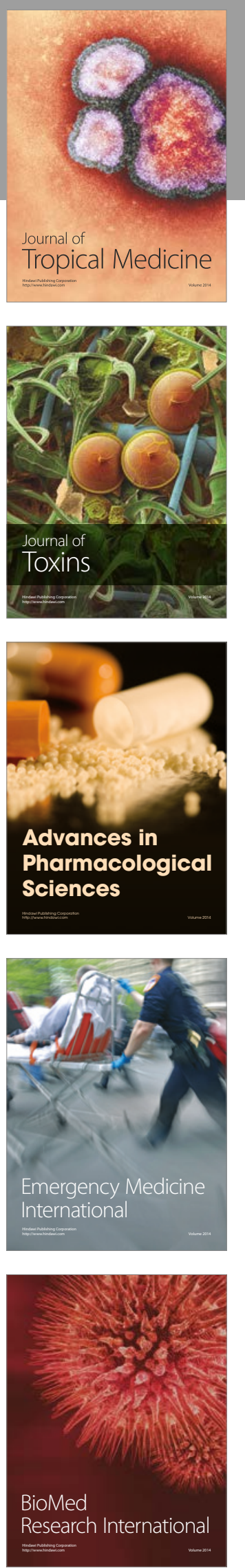
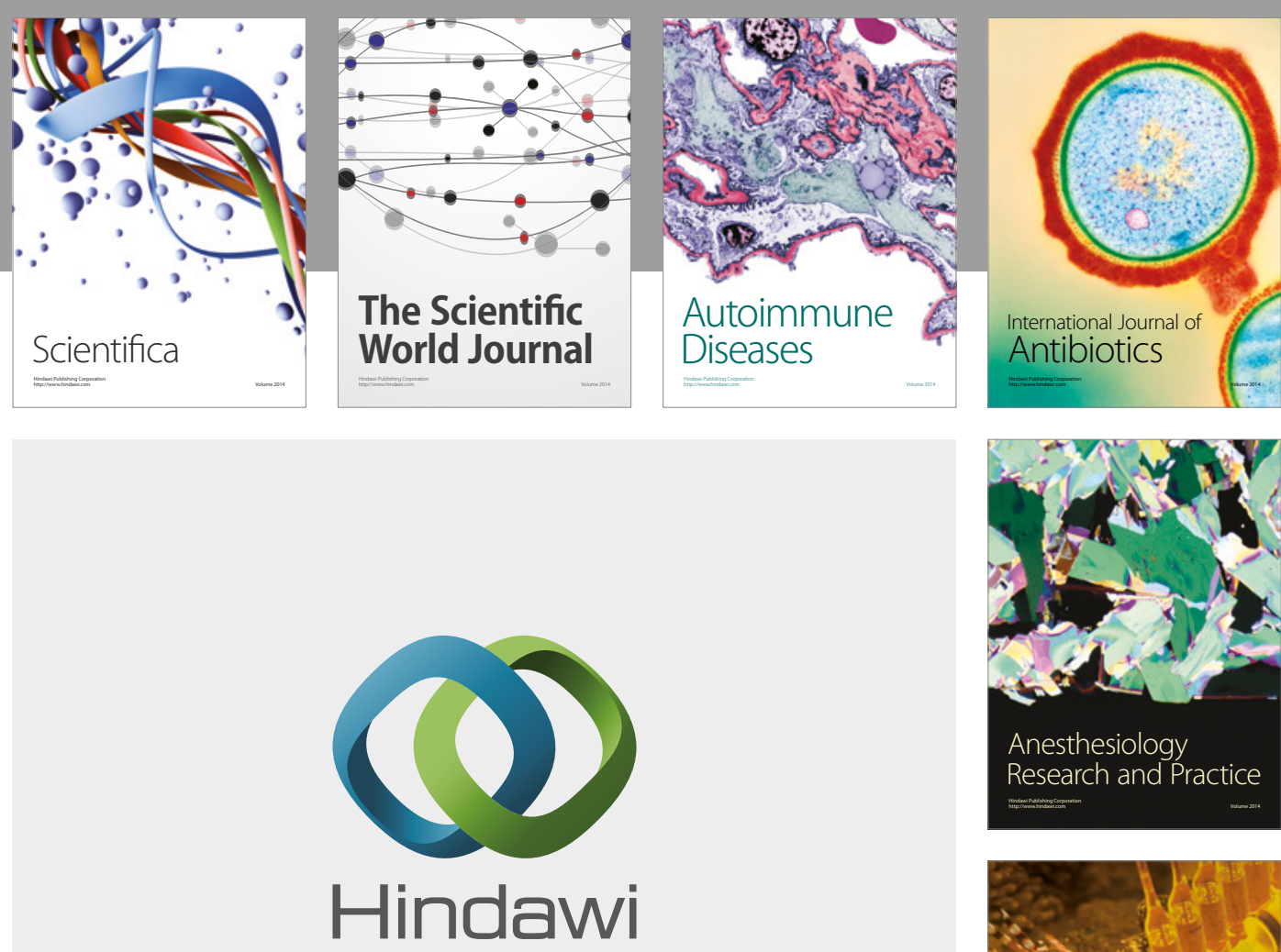

Submit your manuscripts at

https://www.hindawi.com
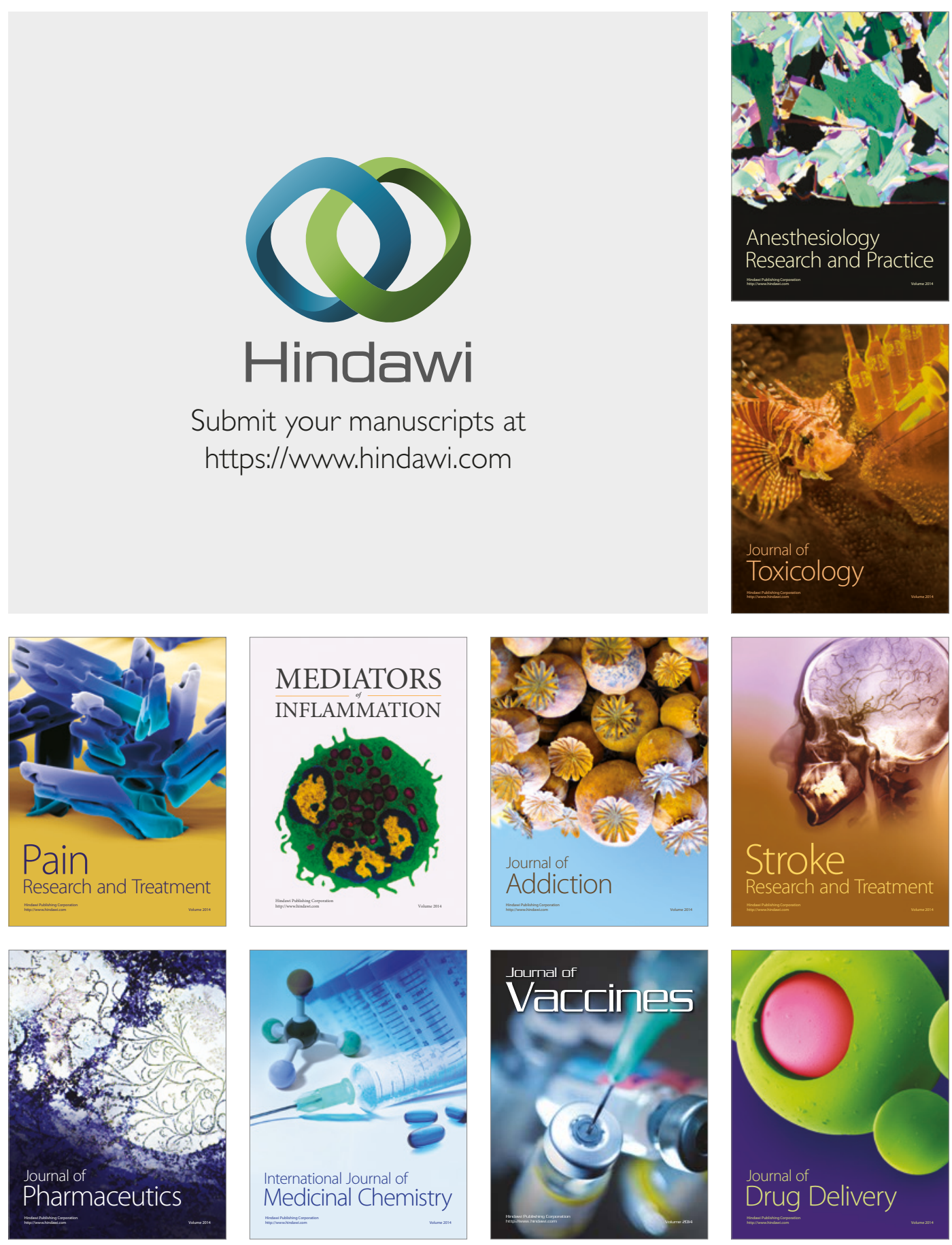